\section{An Inexpensive Training Method for Percutaneous Endoscopic Gastrostomy}

Percutaneous endoscopic gastrostomy (PEG) tube feeding has replaced nasogastric feeding and surgical gastrostomy. Both minor and major complications are associated with PEG placement [1].

Trainees usually learn the procedure by carrying it out on patients while under the supervision of experts. Because of our current situation in Iraq, and lack of the type of training facilities employed else- where [2-4], we have developed a simple and inexpensive method for training our gastrointestinal fellows. The trainees apply the procedure using a watermelon, as shown in Fig. 1- 5.

Watermelons can also be used for teaching other therapeutic procedures, such as injection therapy, polypectomy, or foreign body retrieval. The cost of one good-sized watermelon in Iraq is less than 25 cents.

\section{H. Fayadh (ed)}

The Gastroenterology and Hepatology teaching Hospital, Baghdad, Iraq.

\section{References}

${ }^{1}$ Rimon E. The safety and feasibility of percutaneous endoscopic gastrostomy placement by a single physician. Endoscopy $2001 ; 33: 241-244$

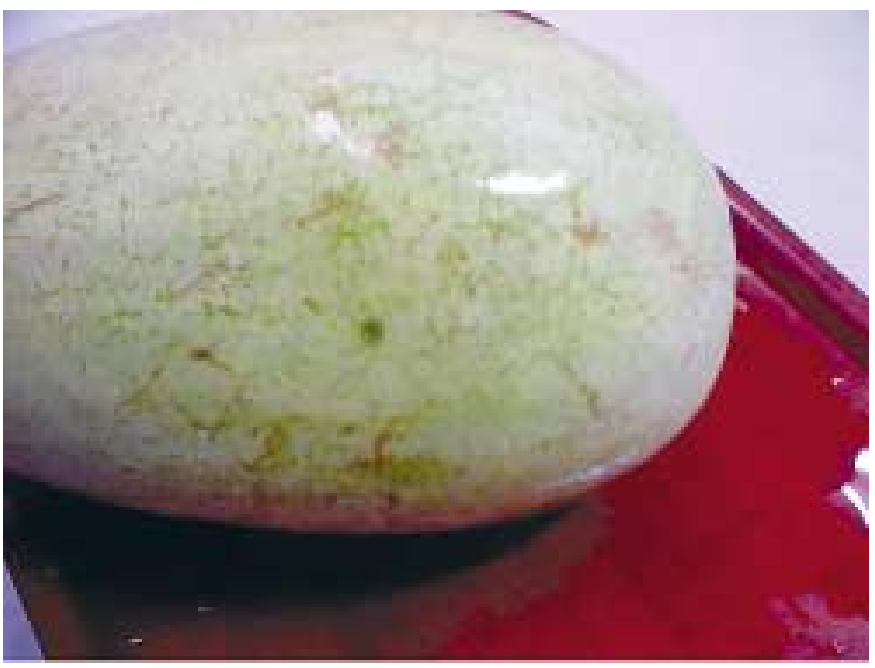

Figure 1 A good-sized watermelon is used.

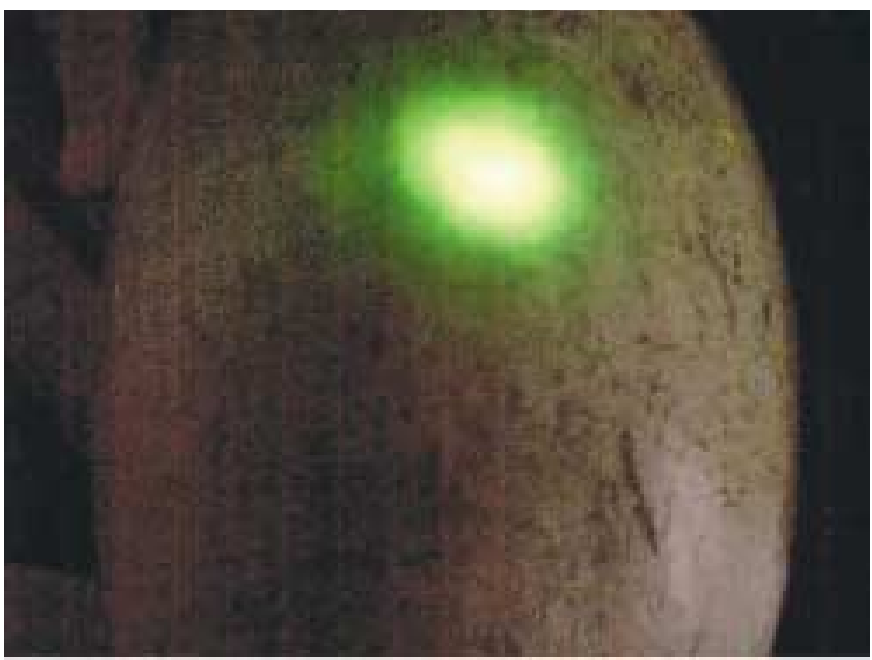

Figure 3 The watermelon is transilluminated using an ordinary gastroscope.

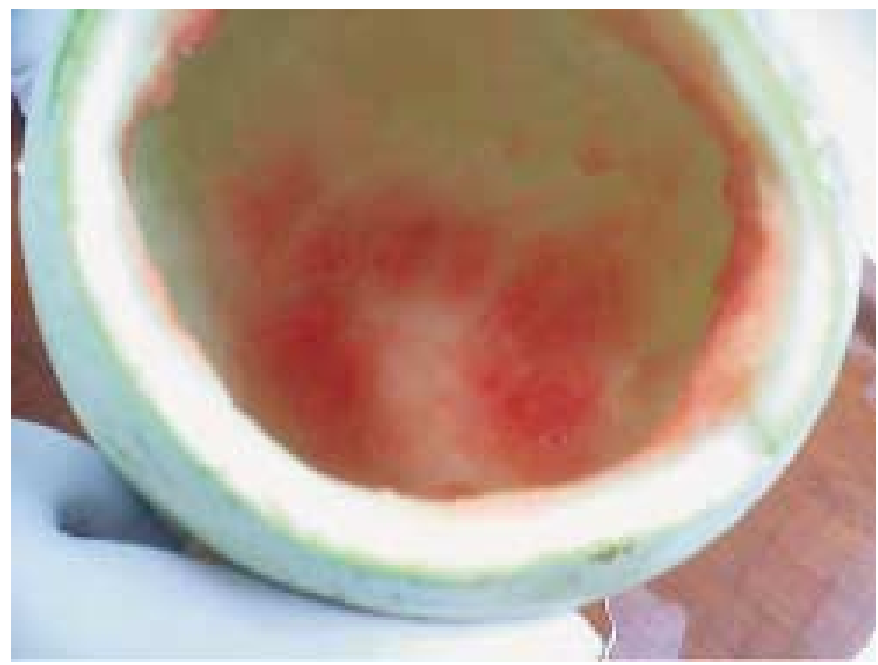

Figure 2 One end of the watermelon is cut and the inside is curetted.

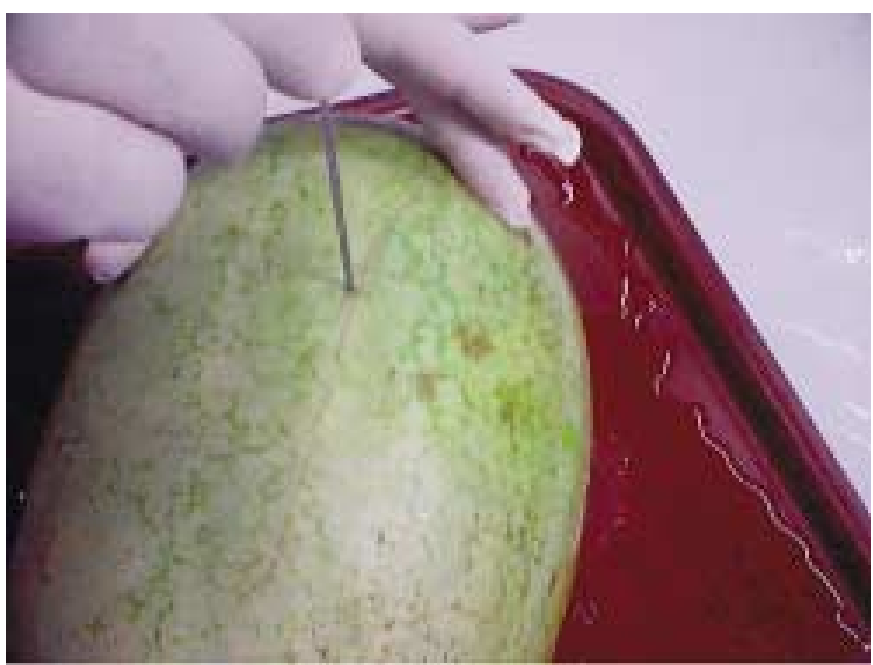

Figure 4 An equipment set for percutaneous gastrostomy by the thread pull-through method is used (GIP Medizintechnik $\mathrm{GmbH}$, E-mail: gip@gip-med.de).The trocar is passed through the transilluminated area. 


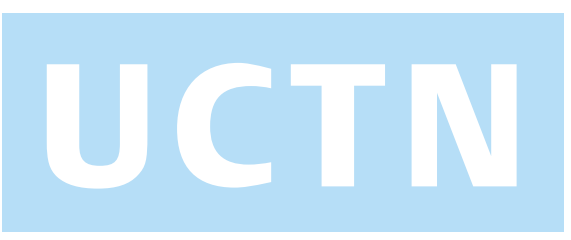

${ }^{2}$ Hochberger J, Maiss J, Magdeburg B et al. Training simulators and education in gastrointestinal endoscopy: current status and perspectives in 2001. Endoscopy 2001; 33: $541-549$

${ }^{3}$ Hochberger J, Maiss J, Hahn EG. The use of simulators for training in gastrointestinal endoscopy. Endoscopy 2002; 34: $727-729$
${ }^{4}$ Ferlitsch A, Glauninger P, Gupper A et al. Evaluation of a virtual endoscopy simulator for training in gastrointestinal endoscopy. Endoscopy 2002; 34: $698-$ 702

\section{Corresponding Author}

\section{H. Fayadh FRCP (ed)}

The Gastroenterology and Hepatology teaching Hospital

Ministry of Health

Baghdad, Iraq

Fax: $\quad$ +9641-415-4642

E-mail: makkihf@yahoo.com makkihf@hotmail.com githos@hotmail.com iraqgit@hotmail.com
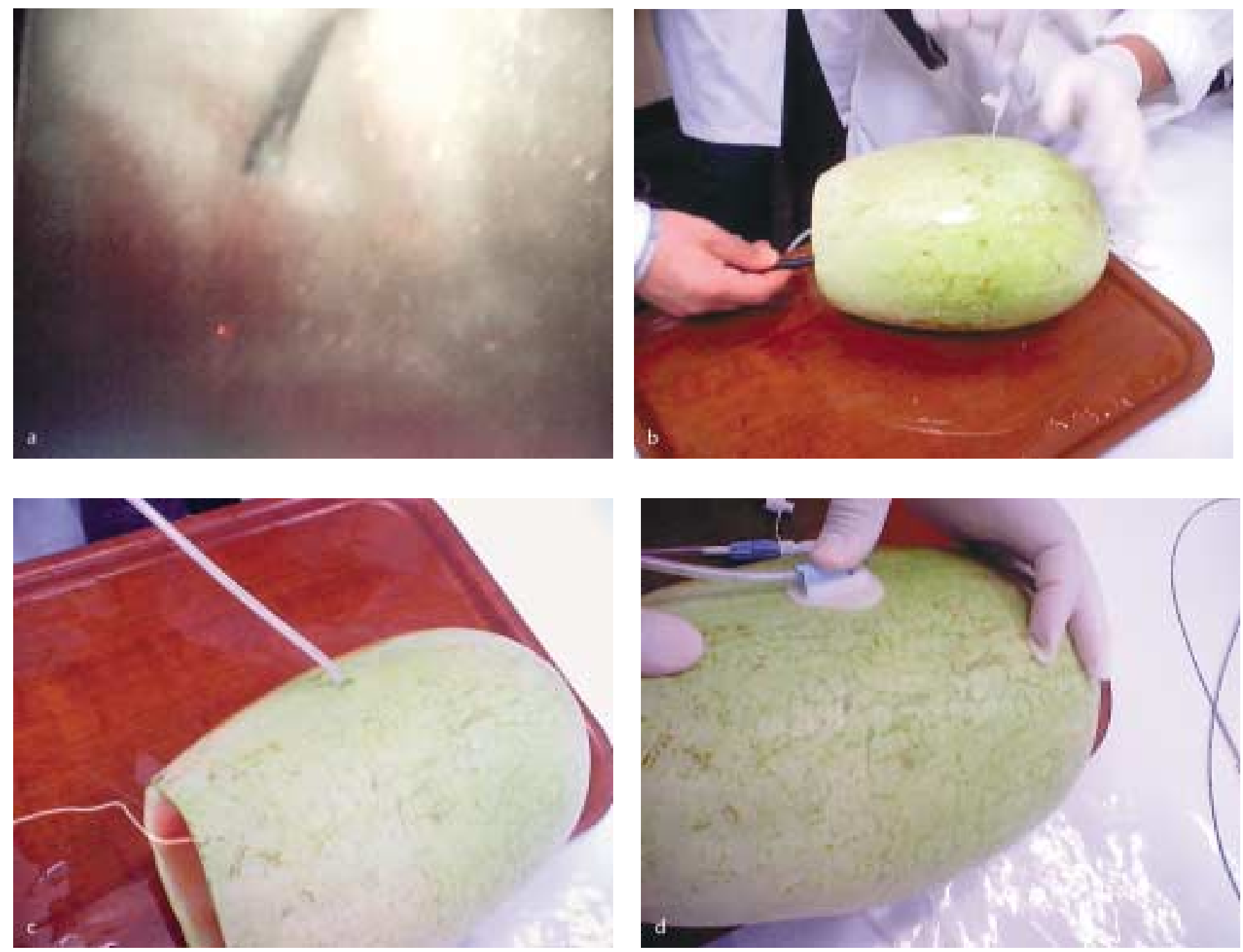

Figure $\mathbf{5}$ The procedure is then carried out analagously to the usual method. a The trocar as seen from inside the watermelon. $\mathbf{b}-\mathbf{d}$ The thread is passed through the scope. The PEG tube is threaded and pulled into position. 